\title{
TREATMENT OF CONVULSIVE STATUS EPILEPTICUS
}

Definition, etiology, treatment, and outcome of convulsive status epilepticus in children and adults are outlined by a group of experts and sponsored by the Epilepsy Foundation of America. Common to all patients, recommendations include a clear predetermined plan of action, prompt administration of appropriate drugs in adequate doses, and attention to the possibility of apnea, hypoventilation, or other metabolic abnormalities. The major drugs include diazepam, lorazepam, phenytoin, and phenobarbital, administered intravenously. If diazepam is used, phenytoin is also necessary to prevent recurrence. After 20-60 min, if status persists, $15-20 \mathrm{mg} / \mathrm{kg}$ phenytoin no faster than $50 \mathrm{mg} / \mathrm{min}$ in adults and $1 \mathrm{mg} / \mathrm{kg} / \mathrm{min}$ in children by IV; monitor ECG and blood pressure; purge IV with normal saline before phenytoin infusion - phenytoin is incompatible with glucose-containing solutions. If phenobarbital is used after a benzodiazepine, apnea often occurs and assisted ventilation is required. Compared to sedative drugs, phenytoin is less likely to depress consciousness. (Dodson WE et al. Treatment of convulsive status epilepticus. Recommendations of the Epilepsy Foundation of America's working group on status epilepticus. IAMA Aug 18 1993; 270:854-859). (Reprints: Dr Dodson, Epilepsy Foundation of America, 4351 Garden City Dr, Landover, MD 20785).

COMMENTS. The details of this action plan will become a fixture in many hospital ERs. The authors are to be commended for a thorough review of this medical emergency. Although prognosis is closely related to the etiology of the status, appropriate and timely therapy reduces the risk of mortality and morbidity. Barry E and Hauser WA discuss the interaction of epilepsy and acute brain disease in 217 patients with status epilepticus (Neurology Aug $1993 ; 43: 1473-1478$ ). The 6-month mortality in this series (37\%) was higher than most other reports, and reflected a high percentage of organic brain disease. In patients with a previous history of epilepsy the mortality was $16 \%$, and in those with no epilepsy but a high proportion of acute brain insults, the mortality rate was $54 \%$. In children, the mortality from status has been reported in the range of $3-8 \%$, and much lower than in the elderly.

\section{BRAIN ABNORMALITIES ON MRI IN PARTIAL EPILEPSY}

The incidence of cerebral abnormalities using MRI in 30 consecutive children, aged 0.9-15.5 years, presenting with intractable complex partial seizures is reported from the Institute of Child Health and Hospital for Sick Children, London, UK. A clinical diagnosis of a temporal lobe focus was made in 19 patients, and all showed hippocampal, temporal lobe abnormalities, or both, on the MRI. Surgery performed in 2 confirmed the radiological diagnosis of hippocampal sclerosis in one and astocytoma in the other. Of 7 children without localizing features clinically, 5 had a hippocampal abnormality, one had atrophy of the right temporal lobe, and one had diffuse cortical change. 